\title{
DONNAN DIALYSIS ASSISTED BY INTERPENETRATING POLYMER NETWORKS FOR CHROMIUM ION TRANSPORT IN AQUEOUS MEDIA
}

\author{
YESID TAPIERO a BERNABÉ L. RIVAS ${ }^{*}$, JULIO SÁNCHEZ ${ }^{b}$ ENRIQUE G. AVILA ${ }^{c}$ \\ ${ }^{a}$ Polymer Department, Faculty of Chemistry, University of Concepción, Chile. \\ ${ }^{b}$ Departamento de Ciencias del Ambiente, Facultad de Química y Biología, Universidad de Santiago de Chile, USACH, Casilla 40, Correo 33, Santiago, Chile. \\ 'Departamento de Estadística, Facultad de Ciencias, Universidad del BioBio, Av. Casilla 5-C, Collao 1202, Concepción, Chile.
}

\begin{abstract}
Macroporous polypropylene (MPP) membranes incorporating poly[sodium (styrene sulphonate)], P(SSNa), and poly[(ar-vinylbenzyl) trimethylammonium chloride],P(ClVBTA) were modified via "in situ" radical polymerization. Modified and unmodified MPP were characterized using SEM and charge density properties. Donnan dialysis was used to transport chromium ions. The results show that the degree of modification varied between $2.5 \%$ and $4.0 \%$, and the water uptake percentage varied between $15 \%$ and $20 \%$. Experimental data for chromium ion transport $(\mathrm{Cr}(\mathrm{III})$ and $\mathrm{Cr}(\mathrm{VI}))$ were fitted to a mathematical model, and a correlation coefficient very close to 1 was obtained. The main parameters of this mathematical fit are $\mathrm{k}$ and a. These parameters report the concentration of chromium ions that converge in the Donnan equilibrium $(\mathrm{k})$ and the response rate of the modified membrane (a).
\end{abstract}

Keywords: Chromium, Donnan dialysis, interpenetrating polymer network, mathematical model, polypropylene.

\section{INTRODUCTION}

Many serious environmental problems are caused by water sources that are polluted by metal and metalloid ions. Chromium, mercury, copper, nickel, cadmium, and arsenic are among these contaminating species. Different oxidation states are presented by chromium ions in water, such as trivalent chromium $\mathrm{Cr}(\mathrm{III})$ and hexavalent chromium $\mathrm{Cr}(\mathrm{VI}) . \mathrm{Cr}(\mathrm{VI})$ is one of the most toxic ion species because it can cause cancer and other serious health problems. These problems depend on the concentration and exposure period. $\mathrm{Cr}(\mathrm{VI})$ ions accumulate in biological systems and are water soluble at all pHs. Recommendations are given by the World Health Organization, where a limit of $0.05 \mathrm{mg} \mathrm{L}^{-1}$ for $\mathrm{Cr}(\mathrm{VI})$ or $\mathrm{Cr}(\mathrm{III})$ is accepted as the maximum permissible concentration. $^{2}$

Concentration and $\mathrm{pH}$ are important factors for the speciation of $\mathrm{Cr}(\mathrm{VI})$ that exists as oxyanions. At the $\mathrm{pH}$ range between 0.75 until 6.45 , the main chromium dominant ions are: chromic acid $\left(\mathrm{H}_{2} \mathrm{CrO}_{4}\right)$, it is the strong acid $\left(\mathrm{H}_{2}\right.$ $\left.\mathrm{CrO}_{4} \leftrightarrow \mathrm{HCrO}_{4}^{-}, \mathrm{K}=10^{-0.75}\right)$; acid chromate $\left(\mathrm{HCrO}_{4}^{-}\right)$, it is deprotonated forms in solutions where has been low concentration of $\mathrm{Cr}(\mathrm{VI})$ less than $0.01 \mathrm{~g} \mathrm{~L}^{-1}$ $\left(\mathrm{HCrO}_{4} \leftrightarrow \mathrm{H}^{+}+\mathrm{HCrO}_{4}^{-}, \mathrm{K}=10^{-6.45}\right)$; dichromate $\left(\mathrm{Cr}_{2} \mathrm{O}_{7}^{2-}\right)$, it is the polymerized form of the $\left(\mathrm{HCrO}^{-}\right)$, when the $\mathrm{Cr}(\mathrm{VI})$ concentration is on the $10^{-2} \mathrm{~mol} \mathrm{~L}^{-1}$ $\left(2 \mathrm{HCrO}_{4} \leftrightarrow \mathrm{Cr}_{2} \mathrm{O}_{7}{ }^{2-}+\mathrm{H} 2, \mathrm{O}, \mathrm{K}=10^{2.2}\right)$ and dichromate acid $\left(\mathrm{H}_{2} \mathrm{Cr}_{2} \mathrm{O}_{7}\right)$, but only if the solution is strongly acidic and the concentration of $\mathrm{Cr}(\mathrm{VI})$ ion is high. ${ }^{3}$ Above $\mathrm{pH} 6.45$, is found a high quantity of chromate $\left(\mathrm{CrO}_{4}^{2-}\right)$ ions throughout the concentration range. ${ }^{3}$

$\mathrm{Cr}(\mathrm{III})$ is an essential element for life, although at certain concentrations, it can damage biological permeability, ionic channels, receptors, and cell membrane enzymes. ${ }^{4} \mathrm{Cr}(\mathrm{OH})_{2}^{+}, \mathrm{Cr}(\mathrm{OH})_{3}{ }^{0}$, and $\mathrm{Cr}(\mathrm{OH})_{4}^{-}$chromyl ions prevail at $\mathrm{pH}$ levels below 3.6. When the $\mathrm{pH}$ is higher, $\mathrm{Cr}$ (III) precipitates as $\mathrm{Cr}(\mathrm{OH})_{3} \mathrm{nH}_{2} \mathrm{O}$.

The painting industry, including both surface plating and chromium electro-plating (decorative and hard plating), stainless steel handwork and other alloys, the concrete industry, etc., are the most important sources of $\mathrm{Cr}(\mathrm{VI})$ and $\mathrm{Cr}(\mathrm{III})$ compound waste. ${ }^{4}$

Currently, the methods for removing these ions are reduction and precipitation, adsorption and ion exchange, together with functional membranes. ${ }^{6-8}$

The most representative membrane technologies used for wasting solutions are reverse osmosis, ultrafiltration, nanofiltration, dialysis, diffusion dialysis, Donnan dialysis, membrane electrolysis, and electrodialysis (e.g., liquid, emulsified, and supported). ${ }^{9-10}$

Donnan dialysis is an attractive membrane method that uses chemical potential differences between membrane sides to generate ionic transport and maintain the electro-neutrality of the two solutions. ${ }^{11}$ Donnan dialysis can also be used to remove $\mathrm{Cr}(\mathrm{VI})$ ions with commercial anion exchange membranes such as SB-6470, AFN, ACM, and Raipore $1030 .{ }^{12}$

Areas such as chemical analysis for pre-concentration, extraction processes, hydrometallurgy, separating acids from their salts, radioactive flow deacidification, removal of copper and zinc using commercial cationic membranes, and removal of inorganic anions such as fluoride, nitrate, bromate, and borate from drinking water can all be achieved with Donnan dialysis. ${ }^{13-17}$

The development of new materials with definitive properties can include interpenetrating polymer networks (IPNs), which is an alternative method to modify microporous membranes. When two or more polymer networks are partially and non-covalently crosslinked on the molecular scale, it allows the formation of IPN architectures. ${ }^{18}$

IPN materials have many applications in biomedicine, water sorption, enzyme immobilization, ion exchange membranes, and fuel cells. ${ }^{19-23}$ Chemically stable commercial porous materials are ideal for developing functional IPN membranes. Two examples of commercially available disposable membranes are micro-porous polypropylene (MPP) or polyethylene. ${ }^{24}$ These polyolefin materials are attractive due to their thermal and mechanical stability and good chemical properties. It is also reported that poly[(ar-vinylbenzyl) trimethylammonium chloride], $\mathrm{P}(\mathrm{ClVBTA})$, is effective for removing chromium ions. ${ }^{25,26}$ Poly[sodium (styrene sulphonate)], $\mathrm{P}(\mathrm{SSNa}$ ), is an efficient cation exchange polymer. $\mathrm{P}(\mathrm{SSNa})$ works to remove metal cations using a polymer-enhanced ultrafiltration technique. ${ }^{27}$

The aim of this paper is to modify MPP support membranes by interpenetrating $\mathrm{P}(\mathrm{ClVBTA})$ and $\mathrm{P}(\mathrm{SSNa})$ networks and to study these membranes for the transport of $\mathrm{Cr}(\mathrm{VI})$ and $\mathrm{Cr}(\mathrm{III})$ ions, fitting this experimental data to a mathematical model that represents Donnan dialysis.

The development of a mathematical model that can predict target changes in solute concentration on both sides of a membrane is an attractive idea. The experimental data for Donnan dialysis were analyzed and adjusted to a theoretical mathematical model.

The mass transport process inside the modified membrane is controlled by Fick's law (see Figure 1). Therefore, the first step is to determine the relationship between the extraction concentration and feed concentration of the target ion, following the linear relationship in equation $1 .^{28}$

$$
C_{i e}=c+b C_{i f}
$$

where the, $\mathrm{C}_{\mathrm{ie}}$, is the target ion concentration in the extraction phase $\left(\mathrm{mol} \mathrm{L}{ }^{-1}\right)$; $\mathrm{c}$, is the mathematical correction factor setting; $\mathrm{C}_{\mathrm{if}}$, is the target ion concentration in the feed phase $\left(\mathrm{mol} \mathrm{L}^{-1}\right)$; and $\mathrm{b}$ is the partition coefficient of the target ion in both aqueous phases.

Under no electrical current, the sum of the flux of feed ion $\left(J_{i}\right)$ and driving ion $\left(J_{j}\right)$ is zero, as in equation 2 :

$$
z_{i} J_{i}+z_{j} J_{j}=0
$$


The $\mathrm{Cr}(\mathrm{VI})$ (see Figure $1 \mathrm{a}$ ), $\mathrm{Cr}(\mathrm{III})$ (see Figure $1 \mathrm{~b}$ ), $\mathrm{Na}^{+}$, and $\mathrm{Cl}^{-}$ions have different charge values $\left(z_{i} \neq z_{j}\right)$. In this case, chromium driving ions diffuse through the membrane from the feed chamber to the extraction chamber. Under electron neutrality, the total concentration of all counterions in the membrane is equal to the fixed ions, which are denoted as the ion exchange capacity, as indicated in equation 3 :

$$
z_{i} C_{i}+z_{j} C_{j}=Q
$$

where the $\mathrm{C}_{\mathrm{i}}$ and $\mathrm{C}_{\mathrm{j}}$ are the anion and cation concentration inside the membrane $\left(\mathrm{mol} \mathrm{L}^{-1}\right)$; $\mathrm{Q}$ is the ion exchange capacity (meq $\left.(\mathrm{g} \text { dry membrane })^{-1}\right)$. The membrane phase requires the following assumptions: a homogeneous material, charge density uniformly distributed throughout the structure, mass transfer process in a pseudo-steady state and in only one direction, control of separation that obeys Donnan equilibrium, a constant partition coefficient of counterions, and a very fast ion exchange reaction on the membrane surface. ${ }^{29}$ The basic conditions of operation can help to identify the different control volumes that compose the Donnan dialysis system, for example, perfectly mixed aqueous solution phases (feed and extraction), constant phase density, environmental temperature, constant ion partition coefficient, constant volume (feed and extraction), and pseudo-steady-state operation.

If Donnan dialysis behavior is represented by the Nernst-Plank equation (eq. 4):

$$
J_{i}=-D_{i}\left(\frac{d C_{i}}{d x}+z_{i} C_{i} \frac{F}{R T} \frac{d \psi}{d x}\right)+q_{i} v
$$

where $\mathrm{D}$, is the ionic diffusion constant $\left(\mathrm{m}^{2} \mathrm{~s}^{-1}\right)$; , is the mass average velocity or convection velocity on the membrane $\left(\mathrm{mol} \mathrm{L}^{-1} \mathrm{~s}^{-1}\right)$; , is the concentration average of ions at the bulk solutions $\left(\mathrm{mol} \mathrm{L}^{-1}\right) ;$, is the concentration gradient respects to the thickness of the membrane $\left(\mathrm{mol} \mathrm{L}^{-1} \mathrm{~m}^{-1}\right)$; , the potential gradient respects to the thickness of the membrane $\left(\mathrm{J} \mathrm{mol}^{-1} \mathrm{~m}^{-1}\right)$; and $\mathrm{F}, \mathrm{R}$ and $\mathrm{T}$ are the Faraday constant $\left(\right.$ Coulombs $\left.\mathrm{mol}^{-1}\right)$, Gas constant $\left(\mathrm{J} \mathrm{K}^{-1}\right.$ $\mathrm{mol}^{-1}$ ) and Temperature (Kelvin).

Equation 4 evaluates the solute fluxes just inside the membrane, and the convective contribution () is negligible. The analytical solution to the NernstPlank equation is in the extraction chamber (eq. 5):

$$
C_{i e}=\frac{C_{i f}^{0}}{2}\left(1-e^{-\frac{t}{\tau}}\right)
$$

where, is the target ion concentration in feed phase at time zero $\left(\mathrm{mol} \mathrm{L}^{-1}\right)$; $\mathrm{t}$ is the time (minute); and, is the time constant (minute).

Equation 5 was substituted into equation 1 to obtain an equation for the feed concentration as a function of time in equation 6 :

$$
\begin{aligned}
& \frac{1}{b}\left[k\left(1-e^{-a t}\right)-c\right]=C_{i f} \\
& \tau=\frac{V L}{2 S D_{i} K} \\
& k=\frac{C_{i f}^{0}}{2} \\
& a=\frac{-1}{\tau}
\end{aligned}
$$

where $a$ is the rate of response of the membrane by the diffusion (minute); $k$ is the value of the equilibrium concentration by the target ion in the extraction phase $\left(\mathrm{mol} \mathrm{L}^{-1}\right) ; V$ is the volumen $\left(\mathrm{m}^{3}\right), S$ is the area of the membrane $\left(\mathrm{m}^{2}\right)$. Parameter () was determined using a linearized equation 6 and then a least squares method. The solution was equation 10:

$$
-a=\frac{\operatorname{Cov}\left(\ln \left(-C_{i e}+k\right), t\right)}{\operatorname{Var}(t)}
$$

where $\operatorname{cov}()$ is the covariance and $\operatorname{var}()$ is the variance. When the time tends to infinity, the target ion concentration converges to (). In this study, the last measurement of the target ion concentration was considered the closest value to ().

The value of () was calculated with the optimal estimator that minimized the square error. ${ }^{28}$

The initial and boundary conditions for target ion $\left(C_{i}(x, t)\right)$ are

$$
\begin{aligned}
& C_{i}(x, 0)=0 \\
& C_{i}(0, t)=K C_{i f}(t) \\
& C_{i}(L, t)=K C_{i e}(t) \\
& C_{i f}(0)=C_{i f}^{0} \\
& C_{i e}(0)=0
\end{aligned}
$$

where the $\mathrm{C}_{\mathrm{i}}$, is the chromium ion concentration $\left(\mathrm{mol} \mathrm{L}^{-1}\right)$; $\mathrm{x}$ is the distance inside the membrane structure $(\mathrm{m})$; $\mathrm{L}$ is the the thickness of the membrane $(\mathrm{m})$; $\mathrm{t}$, is the time (s); and $\mathrm{K}$, is the partition coefficient of the membrane phase.

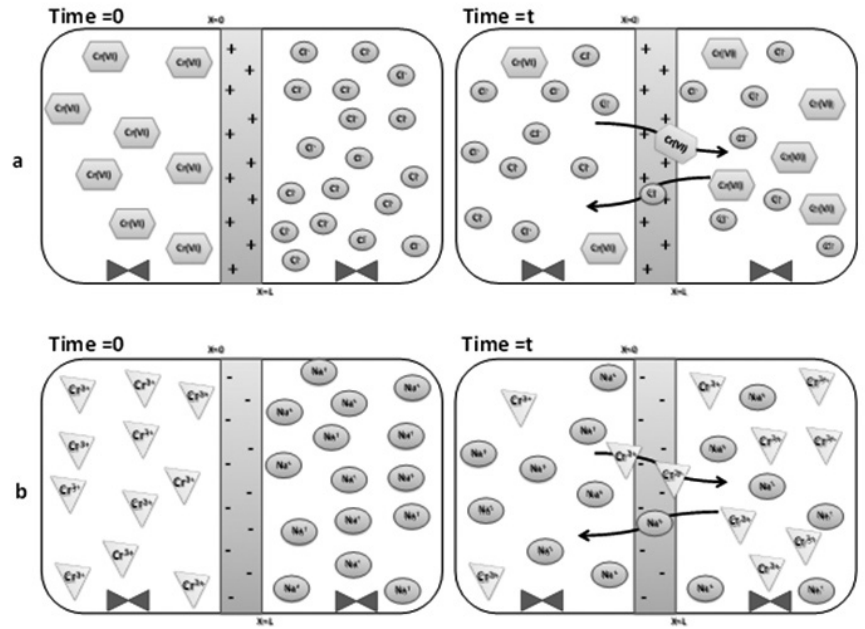

Figure 1. Mass balance scheme through modified membranes. a. $\mathrm{Cr}(\mathrm{VI})$ ion transport using $\mathrm{P}(\mathrm{ClVBTA})$ networks; b.Cr(III) ion transport using $\mathrm{P}(\mathrm{SSNa})$ networks.

\section{EXPERIMENTAL SECTION}

Reagents and materials

MPP membranes (0.6- $\mu \mathrm{m}$ pore size, AN06 Merck Millipore) were used. Sodium styrene sulphonate (SSNa, Aldrich), ammonium persulphate (APS, Merck), ar-[(vinylbenzyl)trimethylammonium chloride] (ClVBTA, Aldrich) and $N, N$-methylene bis acrylamide (MBA, Aldrich) were used for IPN synthesis. The other reagents used to modify the membrane surfaces were $15 \mathrm{kDa}$ polyvinyl alcohol (PVA, Merck), $15 \mathrm{kDa}$ poly(ethyleneimine) (PEI, Aldrich), glutaraldehyde (Ga) (Aldrich), divinylsulphone (Aldrich), $200 \mathrm{kDa}$ poly(ar-[(vinylbenzyl)trimethylammonium chloride]) (P(CIVBTA), SigmaAldrich), $200 \mathrm{kDa}$ poly(sodium 4-styrenesulphonate) ( $\mathrm{P}(\mathrm{SSNa})$, Aldrich), ethanol (Merck), and Type I deionized water from Thermo Fisher TKA Scientific. Potassium dichromate (Cr(VI), Merck) and chromium (III) nitrate nonahydrate (Cr(III), Merck) were the chromium sources. Hydrochloric acid (Merck), nitric acid (Merck), and sodium hydroxide (Merck) were used to adjust the $\mathrm{pH}$. A UB- $10 \mathrm{pH} / \mathrm{mV}$ meter from Denver Instruments was used to measure the $\mathrm{pH}$. Sodium chloride (Merck) was used as the extraction agent.

A stirred-cell filtration unit (Millipore, model 8050) was used to inject the reactive solution into the MPP membrane pores. An aluminum flat reactor was used for radical polymerization.

A dielectric barrier discharge (DBD) plasma reactor was used to activate 
the membrane surfaces. The components and operating modes of the DBD were previously published. ${ }^{30}$

A Cary 100 scan UV-visible spectrophotometer from Varian was used to directly measure the $\mathrm{Cr}(\mathrm{VI})$ and $\mathrm{Cr}(\mathrm{III})$ ion concentrations. The $\mathrm{Cr}(\mathrm{VI})$ ion concentration was measured at 350 and $372 \mathrm{~nm}$ at $\mathrm{pH} 3.0$ and 9.0 respectively. ${ }^{31} \mathrm{The} \mathrm{Cr}(\mathrm{III})$ ion concentration was measured at 407 and $573 \mathrm{~nm}$ for acidic $\mathrm{pH}^{31}{ }^{31}$ Origin ${ }^{\circledR}$ Pro 8 software was used to draw the profile graphics, and mathematical modeling was performed using $\mathrm{R}$ statistical software.

Synthesis of $P(C l V B T A)$ and $P(S S N a)$ interpenetrating polymer networks
An aqueous mixture of $50 \% \mathrm{w} / \mathrm{w}$ ethanol was used to wash the membranes and wet the pores. The functional monomer (CIVBTA or SSNa), crosslinking reagent (MBA), and initiator reagent (APS) in a $10-\mathrm{mL}$ reaction solution were passed through the membrane using a stirred-cell filtration unit with nitrogen gas and a pressure of 1 bar. APS (1 mol \%) was used as the radical initiator. The "in situ" free-radical polymerization was performed inside the membrane pores at $70^{\circ} \mathrm{C}$ for $24 \mathrm{~h}^{26}$ The samples were dried in an oven at $50^{\circ} \mathrm{C}$ and stored in a silica dryer for $24 \mathrm{~h}$. Table 1 shows the experimental design of IPN formation. For MC6 and MA7 membranes, both sides of the polypropylene membrane contacted the plasma argon for 1 min using plasma activation.

Table 1. Experimental design of interpenetrating polymer network (IPN) synthesis inside pore polypropylene membranes.

\begin{tabular}{|c|c|c|c|c|}
\hline \multirow[b]{2}{*}{ Sample code } & \multicolumn{4}{|c|}{ IPN Conditions } \\
\hline & $\begin{array}{c}\text { Crosslinker / } \\
\% \text { MBA }\end{array}$ & $\begin{array}{l}\text { Monomer / } \\
\mathrm{mol} \mathrm{L}^{-1}\end{array}$ & $\begin{array}{c}\text { Number of injections } \\
\text { at } 1 \text { bar }\end{array}$ & Polymer \\
\hline & & & & $\mathrm{P}(\mathrm{SSNa})$ \\
\hline $\mathrm{MC} 1$ & 2 & $4.0 \times 10^{-1}$ & 1 & --- \\
\hline $\mathrm{MC} 2$ & 6 & $4.0 \times 10^{-1}$ & 1 & --- \\
\hline MC3 & 6 & $4.0 \times 10^{-1}$ & 1 & $200 \mathrm{kDa}$ \\
\hline MC4 & 8 & $4.0 \times 10^{-1}$ & 1 & $200 \mathrm{kDa}$ \\
\hline MC5 & 4 & $4.0 \times 10^{-1}$ & 1 & $200 \mathrm{kDa}$ \\
\hline MC6 & 6 & $4.0 \times 10^{-1}$ & --- & --- \\
\hline & & & & $\mathrm{P}(\mathrm{ClVBTA})$ \\
\hline MA1 & 2 & $2.0 \times 10^{-1}$ & 3 & \\
\hline MA2 & 2 & $4.0 \times 10^{-1}$ & 3 & \\
\hline MA3 & 2 & $6.0 \times 10^{-1}$ & 1 & \\
\hline MA4 & 6 & $4.0 \times 10^{-1}$ & 1 & $200 \mathrm{kDa}$ \\
\hline MA5 & 6 & $4.0 \times 10^{-1}$ & 1 & $200 \mathrm{kDa}$ \\
\hline MA6 & 8 & $4.0 \times 10^{-1}$ & 1 & --- \\
\hline MA7 & 6 & $4.0 \times 10^{-1}$ & --- & \\
\hline
\end{tabular}

Characterization

The characterization of the modified interpenetrating polymer networks membrane samples was developed through:

Volumetric flux

The time required for $50 \mathrm{~mL}$ of distilled deionized water to pass through a modified membrane was measured. A pressure of 1 bar was maintained for all tests. A stirred-cell filtration unit (Amicon) was used during this step using nitrogen gas as the pressure source.

Modification degree

The modification ( $\% \Delta \mathrm{G}_{\mathrm{m}}$ ) was measured gravimetrically. First, the unmodified membranes were weighed. These membrane samples (dried samples) were weighed after the modification. The $\% \Delta \mathrm{G}_{\mathrm{M}}$ was determined from equation 16

$$
\% \Delta G_{M}=\frac{\left(w_{f}-w_{0}\right)}{w_{0}} 100
$$

where $w_{f}$ is the dry IPN membrane weight $(\mathrm{g})$ and $w_{0}$ is the unmodified membrane weight $(\mathrm{g})$.

Water uptake percentage

The weight of the dried IPN modified membrane was measured before wetting with distilled deionized water for $24 \mathrm{~h}$. During this period, the samples reached swelling equilibrium, and all tests occurred at room temperature. The excess water was removed from the modified wet membranes using absorben paper in all tests. The weight of the modified membranes was measured three times. The water uptake percent $\left(\% \Delta \mathbf{W}_{w}\right)$ was calculated from equation 17 :

$$
\% \Delta W_{w}=\frac{\left(W_{w e t}-W_{d r y}\right)}{W_{d r y}} 100 \%
$$

where $W_{\text {wet }}$ is the wet IPN membrane weight (g) and $W_{d r y}$ is the dry IPN membrane weight $(\mathrm{g})$.

Scanning Electron Microscopy (SEM)

This technique was used to analyze the morphological changes in the modified and unmodified membranes. A $20000 \mathrm{kV}$ JOEL microscope (JSH 6380LV model) was used.

Charge density properties

Brookhaven Zeta Plus equipment was used. The samples were cut into thin pieces and submerged in $0.05 \mathrm{M} \mathrm{KCl}$ at $\mathrm{pH} 3.0,5.0,7.0$, and 9.0. The $\mathrm{pH}$ was controlled using $\mathrm{HCl}$ and $\mathrm{NaOH}$. The electrokinetic potential (५) was determined from the ionic mobility $\left(\mu_{\mathrm{e}}\right)$ using the Smoluchowski Equation (eq. 18):

$$
\mu_{e}=\frac{\varepsilon * \varsigma}{\eta}
$$

The charge density $\left(\sigma^{*}\right)$ was calculated from the electrokinetic potential (५) using equation 19:

$$
\sigma^{*}=\left[\left(7.331 \times 10^{-3} C\right)^{1 / 2} \sinh (\varsigma / 51.39)\right] \frac{1.0 \AA^{2}}{\left(1.0 \times 10^{-10}\right)^{2}}
$$

where $\mu_{\mathrm{e}}$ is the ionic electrophoretic mobility $\left[\left(\mu \mathrm{s}^{-1} \mathrm{~V}^{-1} \mathrm{~cm}\right)\right], \varepsilon$ is the liquid permittivity $\left[\mathrm{J} \mathrm{V}^{-1} \mathrm{~m}^{-1}\right], \mathrm{C}$ is the $\mathrm{KCl}$ concentration, $\eta$ is the liquid viscosity, $\sigma^{*}$ is the charge density, and $\zeta$ is the electrokinetic potential or zeta potential $[\mathrm{mV}] .{ }^{32}$ Donnan dialysis

A two-chamber diffusion cell (feed and extraction phases) was separated using an IPN membrane. Each chamber had a $100 \mathrm{~mL}$ capacity and was filled with $50 \mathrm{~mL}$ of work solution for the tests (see Figure 1). 
Experimental design

Modified membranes with $\mathrm{P}(\mathrm{ClVBTA})$ networks were used for $\mathrm{Cr}(\mathrm{VI})$ ion transport, and modified membranes with $\mathrm{P}(\mathrm{SSNa})$ networks were used to study $\mathrm{Cr}$ (III) ion transport. For Cr(III) ions, the feed chamber was filled with the $\mathrm{Cr}$ (III) acid solution, and the extraction chamber was filled with $\mathrm{HNO}_{3}$ solution. In other experiments, the extraction chamber was filled with a mixture of $1 \mathrm{M}$ $\mathrm{NaCl}$ and $0.01 \mathrm{M} \mathrm{HNO}$. Samples were removed from the extraction chamber to measure the $\mathrm{Cr}(\mathrm{III})$ ion concentration. A $3 \mathrm{~mL}$ sample was taken every 60 min for 4 and $6 \mathrm{~h}$. Direct UV-visible spectrophotometry was used to measure the $\mathrm{Cr}$ (III) ion concentration ${ }^{31}$ The samples were returned to the extraction chamber after measuring the $\mathrm{Cr}(\mathrm{III})$ ion concentration. For $\mathrm{Cr}(\mathrm{VI})$ ion, the feed chamber was filled with the $\mathrm{Cr}(\mathrm{VI})$ solution, and the extraction chamber was filled with a $1 \mathrm{M} \mathrm{NaCl}$ solution. Every 60 min for 18 to $24 \mathrm{~h}, 3 \mathrm{~mL}$ was extracted from the extraction chamber. Direct UV-visible spectrophotometry was used to measure the $\mathrm{Cr}(\mathrm{VI})$ ion concentration. The samples were returned to the extraction chamber after measuring the $\mathrm{Cr}(\mathrm{VI})$ ion concentration. Table 2 shows the experimental conditions for the transport study.

Table 2. Experimental conditions to evaluate $\mathrm{Cr}(\mathrm{VI})$ and $\mathrm{Cr}(\mathrm{III})$ ion transport.

\begin{tabular}{|c|c|c|c|c|c|}
\hline Experiment & {$[\mathrm{Cr}(\mathrm{III})] / \mathrm{mol} \mathrm{L}^{-1}$} & $\mathrm{pH}_{\text {feed phase }}$ & $\mathrm{pH}-_{\text {extraction phase }}$ & \multicolumn{2}{|c|}{$\begin{array}{l}\text { Extraction agent } \\
\qquad / \mathrm{mol} \mathrm{L}^{-1}\end{array}$} \\
\hline /P(SSNa) & & & & {$\left[\mathrm{HNO}_{3}\right]$} & {$[\mathrm{NaCl}]$} \\
\hline 1 & $4 \times 10^{-2}$ & 2.0 & 1.0 & $1 \times 10^{-1}$ & --- \\
\hline 2 & $4 \times 10^{-2}$ & 2.0 & 2.0 & $1 \times 10^{-2}$ & 1 \\
\hline & {$[\mathrm{Cr}(\mathrm{VI})] / \mathrm{mol} \mathrm{L}^{-1}$} & & & & \\
\hline $\mathrm{P}(\mathrm{ClVBTA})$ & & & & \multicolumn{2}{|c|}{$[\mathrm{NaCl}]$} \\
\hline 3 & $5 \times 10^{-4}$ & 3.0 & 3.0 & \multicolumn{2}{|c|}{1} \\
\hline 4 & $5 \times 10^{-4}$ & 9.0 & 9.0 & \multicolumn{2}{|c|}{1} \\
\hline
\end{tabular}
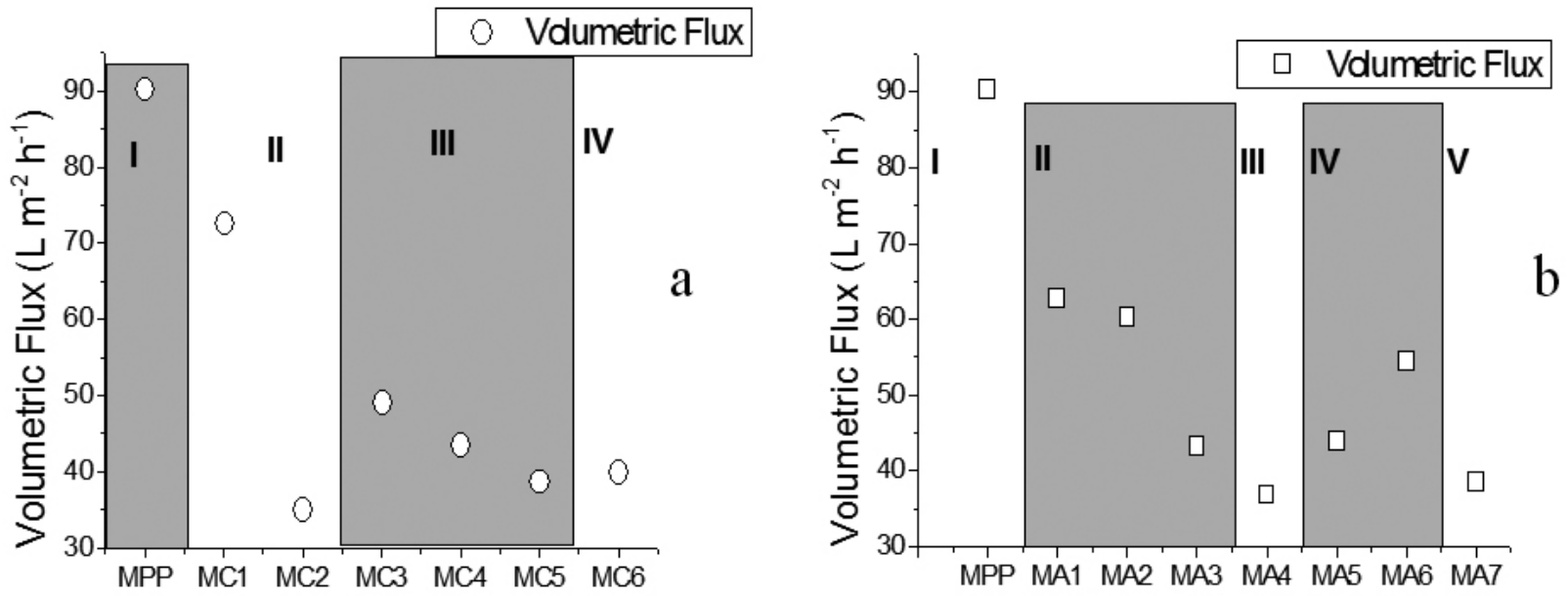

Figure 2. Volumetric flux of water through: a. P(SSNa)-modified membranes and b. P(ClVBTA)-modified membranes.

\section{RESULTS AND DISCUSSION}

\section{Characterization}

The volumetric flux of water by the modified membranes was low relative to the MPP sample for both anionic and cationic membranes. Figure 2a shows the tendency of volumetric water flux through membranes modified with $\mathrm{P}(\mathrm{SSNa})$. In zone I, the volumetric flux of MPP is indicated as a reference, while in zone II, the passage of water is influenced by the number of injections and the MBA concentration of the MC1 and MC2 membranes. The resistance to water fluency was higher for $\mathrm{MC} 2$ because the mass of $\mathrm{P}(\mathrm{SSNa})$ increased more inside the structure compared to MC1. Zone III (MC3, MC4, and MC5 membranes with $\mathrm{P}(\mathrm{SSNa}) 200 \mathrm{kDa}$, lineal) shows resistance to volumetric flux, which increases independent of MBA quantity. It is possible that the internal morphological structure of MPP leads to this irregularity. The result for MC6 (zone IV) is very similar to that of zone III. The lowest volumetric flux for membranes modified with $\mathrm{P}(\mathrm{SSNa})$ is in $\mathrm{MC} 2$. In general, this can be attributed to the $\mathrm{P}(\mathrm{SSNa}) \mathrm{IPN}$ morphology in the layer shape. These results will be shown in the SEM analysis.

Figure $2 \mathrm{~b}$ shows five representative zones that depend on the method, synthesis conditions and internal morphological structure of MPP. Zone I is the reference parameter of the MPP. Zone II (MA1, MA2 and MA3) shows modified membranes with changes in the injection number and CIVBTA concentration. The decrease in volumetric flux in this zone depends mainly on the monomer CIVBTA concentration. The minimum volumetric flux values are obtained in zones III and V. This was achieved for MA4 and MA7, which are modified membranes with $6 \mathrm{~mol} \%$ of MBA crosslinking agent but different methods of preparation. The internal structure and initial pore distribution of MPP may control the growth of $\mathrm{P}(\mathrm{ClVBTA})$ polymer networks.

In zone IV (MA5 and MA6, membranes with 200-kDa P(CIVBTA)), it is possible to observe a reversal in the volumetric flux trend that increased when the MBA crosslinking agent was used. This may be due to the formation of domains that separate the phases due to hydrophobic repulsion between the polypropylene and hydrophilic networks.

The change in volumetric water flux decreased for these modified membranes because $\mathrm{P}(\mathrm{SSNa})$ and $\mathrm{P}(\mathrm{ClVBTA})$ IPN grew inside the pores and produced resistance to water. This is the first evidence of the modification process. The $\mathrm{P}(\mathrm{SSNa})$ IPNs were deeper for the PP membrane than the $\mathrm{P}(\mathrm{ClVBTA})$ IPNs. The $\mathrm{P}(\mathrm{ClVBTA})$ IPNs agglomerated on the surface in large quantities, which makes it easier to access quaternary ammonium groups. These results are supported by SEM analysis. 

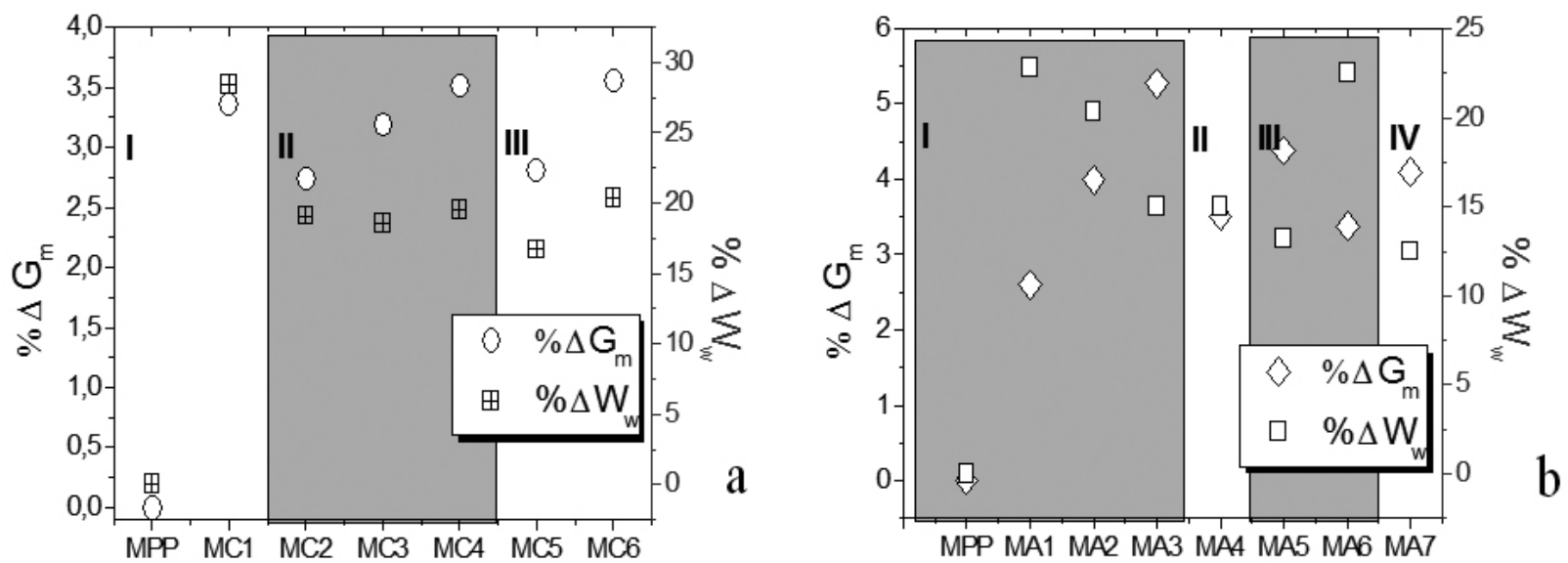

Figure 3. Optimum values of modified degree, $\% \Delta \mathrm{G}_{\mathrm{m}}$, and water uptake percentage, $\% \Delta \mathbf{W}_{\mathrm{w}}$.

The evaluation of the modified MPP membranes must consider the change in the modification percent degree and the water uptake percentage. These tests confirm the complete modification. Figure 3 a shows the tendency of the modification percent degree, and in zones I, II, and III, these values increased as a function of MBA concentration. The highest percent modifications for al of the synthesized P(SSNa) IPN membranes were achieved for MC6 (3.53\%), MC5 (3.52\%), and MC1 (3.36\%). However, the water uptake percentages were not homogeneous and do not follow the tendency of the modification percent degree. The modifications (\%) of the MC1 and MA2 (see Figure 3b) membranes were similar, while their percent water uptake and volumetric fluxes were smaller for higher injection quantities.

Zone I in Figure $3 \mathrm{~b}$ shows that the modification percent degree increases with the ClVBTA monomer concentration in contrast to the water uptake percentage. If the concentrations of $\mathrm{P}(\mathrm{ClVBTA})$ networks increase and the internal space of the MPP decreases, the functional networks cannot swell freely. The MA1 and MA2 membranes had increasing percent modifications because they are a function of injection number and monomer concentration, but if the monomer concentration is $6.0 \times 10^{-1} \mathrm{~mol} / \mathrm{L}$ (MA3), only one injection is necessary. Zone III and zone I have the same tendencies.

The highest percent modification for IPN membranes with the change in monomer concentration and injection number was achieved by MA3 (5.27\%), while the highest percent modification for the semi-IPN membranes was achieved by MA5 (4.38\%), and the highest change in MBA percent for IPN was achieved by MA4 (3.5\%) and MA7 (4.1\%). Similar results are obtained in zones II and IV.

The membranes synthesized via a superficial activation plasma technique (MC6 and MA7) exhibited percent modifications, percent water uptake, and water volumetric flux changes that are similar to those of the semi-IPN membranes (MC5 and MA6).
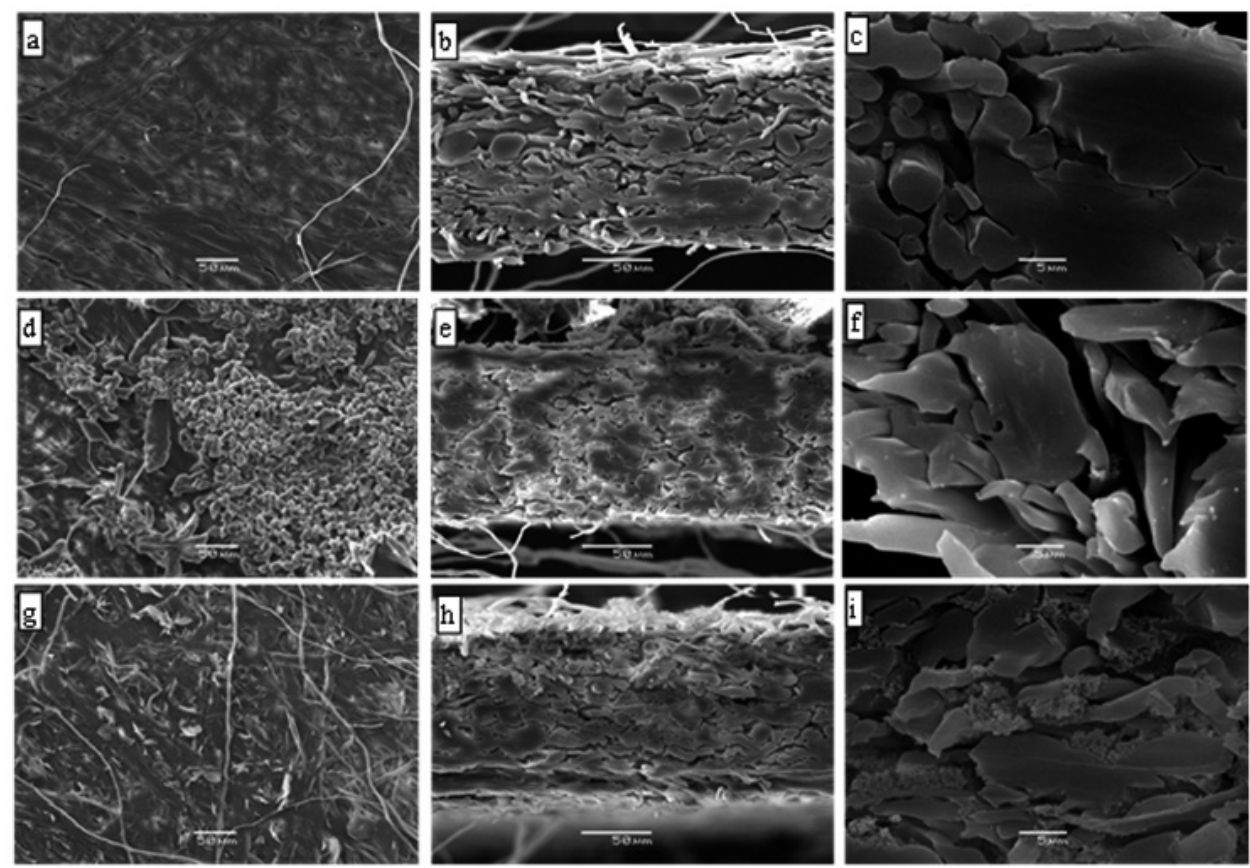

Figure 4. SEM images. MPP (a. superficial face to $50 \mu \mathrm{m}$, and $\times 300$. b. Cross-sectional area to $50 \mu \mathrm{m}$, and $\times 300$. c. Cross-sectional area close to the superficial face to $5 \mu \mathrm{m}$, and $\times 3000$ ). MA4,modified membrane with $\mathrm{P}(\mathrm{ClVBTA})$ (d. superficial face to $50 \mu \mathrm{m}$, and $\times 300$. e. Cross-sectional area to $50 \mu \mathrm{m}$, and $\times 300$. f. Cross-sectional area close to the superficial face to $5 \mu \mathrm{m}$, and $\times 3000$ ). MC2, Modified membrane with P(SSNa) (g. superficial face to $50 \mu \mathrm{m}$, and $\times 300$. h. Cross-sectional area to $50 \mu \mathrm{m}$, and $\times 300$. i. Cross-sectional area close to the superficial face to $5 \mu \mathrm{m}$, and $\times 3000)$. 
The membrane morphologies of the $\mathrm{P}(\mathrm{ClVBTA})$ and $\mathrm{P}(\mathrm{SSNa})$ network membranes were compared to the unmodified MPP membrane. Figure $4 \mathrm{a}$ shows the morphology of unmodified MPP in which the membrane face had an intertwined fiber structure, low porosity, and a smooth superficial aspect. In contrast, the cross-sectional area shows high density, based on the thick and compacted PP fibers (see Figure 4b). These results represent an anisotropic membrane (see Figure 4c). ${ }^{33}$

The highest $\mathrm{P}(\mathrm{ClVBTA})$ network concentration was found on the superficial face relative to the observed membrane cross-section. Figures $4 d$, e, and $f$ show the results of the representative MA4. For example, in Figure 4d, two different phases were observed: the first was the PP fibers, and the second was the $\mathrm{P}(\mathrm{ClVBTA})$ networks. Figure $4 \mathrm{e}$ shows the PP fibers that provide support and mechanical resistance to amorphous IPN materials, while the IPN materials produced the ion exchange. Additionally, these results indicate a change in micro-structural homogeneity (see Figure $4 \mathrm{f}$ ) compared to the unmodified MPP membrane (see Figure 4c)

The morphology achieved in this investigation (P(ClVBTA) networks) was very similar to the results of the grafted and copolymerized 4-vinylpiridinium monomer within MPP membranes because they are pore-narrowing and pore- blocking; the smoother surface is covered by a thin polymer layer, and the surface membranes are evenly modified. ${ }^{34}$ This makes it possible to observe some places with the amorphous materials of the functional polymer.

The $\mathrm{P}(\mathrm{SSNa})$ network particles were smaller and less agglomerated than in the $\mathrm{P}(\mathrm{ClVBTA})$ network. This result is presented in Figures $4 \mathrm{~g}, \mathrm{~h}$, and $\mathrm{i}$. The MC2 representative membrane exhibited two phases relative to the unmodified MPP membrane (see Figure $4 \mathrm{~g})$. The $\mathrm{P}(\mathrm{SSNa})$ was enclosed in the MPP structure and covered the entire MPP fiber surface like paint (see Figure $4 \mathrm{~h}$ and $\mathrm{i}$ ). In the cross-section region, this membrane maintains the same morphology as the MPP sample (see Figures $4 \mathrm{~b}$ and $\mathrm{g}$ ). The P(SSNa) networks were generally more homogeneous and covered more PP fibers than the $\mathrm{P}(\mathrm{ClVBTA})$ networks (see Figure 4i). In general, the membranes exhibited low IPN concentrations in their cross-sections due to the hydrophobic nature of the isotactic MPP and low pore uniformity due to their highly asymmetric character. $^{35,36}$

SEM analysis of the polyethylene and polypropylene membranes modified by grafting $\mathrm{P}(\mathrm{SSNa})$ was superficially similar to the present results. The analysis found a structural surface change in which small particles with small pores appeared, indicating that the membrane surface was unevenly modified. ${ }^{37}$

Charge density properties
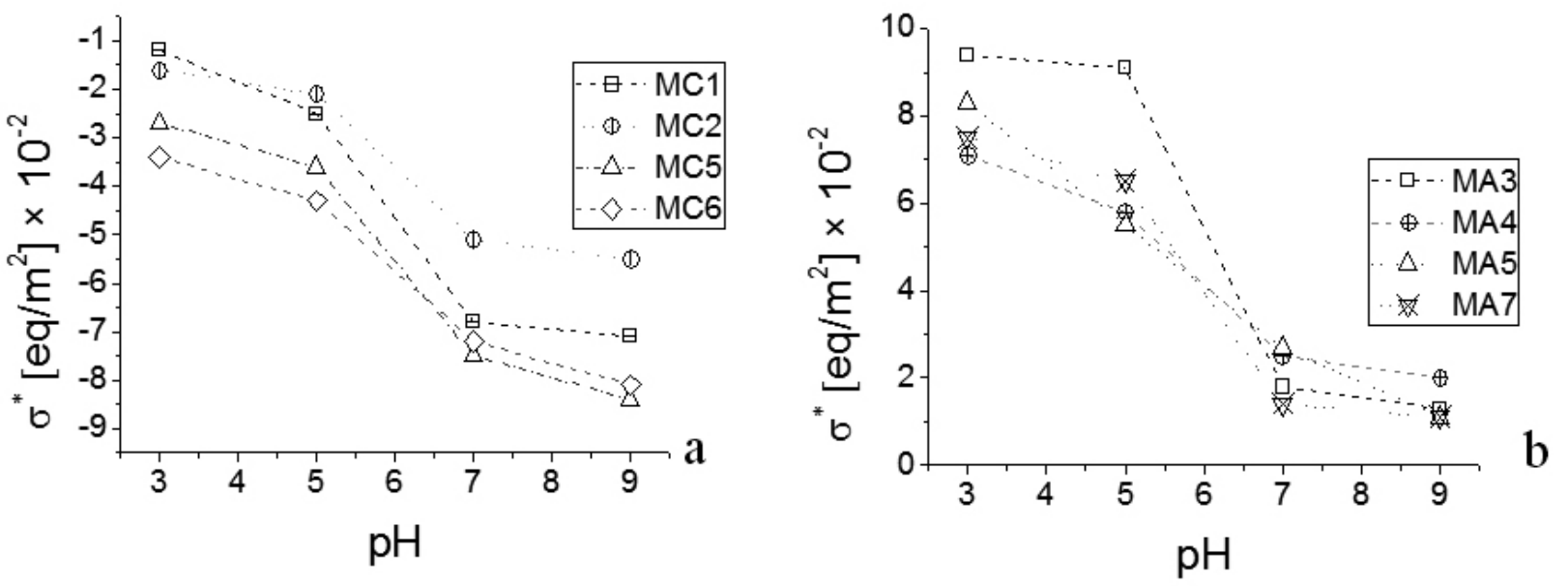

Figure 5. Charge density profile derivation of the electrokinetic potential of modified membranes: a. P(SSNa)-modified membranes; and b. $\mathrm{P}(\mathrm{ClVBTA})$-modified membranes.

The MPP membrane is hydrophobic without any modification and has no ionic functional groups, which makes the membrane inert to electric fields. The superficial charge density distributions produced by the ionic functional groups were analyzed using the electrokinetic properties. Electrokinetic potential can be used to evaluate membrane stability, polyvalent ion absorption capacity, and pore size. ${ }^{38}$ The electrokinetic potential is the fixed charge potential difference (quaternary ammonium and sulphonate groups) between the mobile ionic charges in the absorption layer. The change in $\mathrm{pH}$ caused the networks to extend or compact their segments. The charge density values depend on previously described behavior. ${ }^{39}$

Figure 5a shows a tendency to decrease charge density in membranes modified with $\mathrm{P}(\mathrm{SSNa})$ networks when the $\mathrm{pH}$ increases. At $\mathrm{pH} 7.0$ to 9.0, the excess $\mathrm{OH}^{-}$ions repelled the sulphonate groups fixed in the network and favored the movement of the $\mathrm{Na}^{+}$counterion in the diffusion layer. In this range, Donnan exclusion is favorable. At $\mathrm{pH}$ 3.0, the charge density properties become less negative because $\mathrm{H}^{+}$ions compete with $\mathrm{Na}^{+}$ions in the diffusion layer. The response signal of the membranes modified by an electric field depends on the modification percentage degree of the P(SSNa) IPN concentrations and the internal distribution. A more intense signal was achieved for MC5 and MC6 compared to the other test samples.

Figure $5 \mathrm{~b}$ shows the profile of the charge density for membranes modified with $\mathrm{P}(\mathrm{ClVBTA})$ networks. These membranes exhibited high charge density when the $\mathrm{pH}$ was 3.0 and depend on the excess $\mathrm{H}^{+}$repelling the quaternary ammonium groups. Between $\mathrm{pH} 5.0$ and 9.0, the charge density decreases due to $\mathrm{OH}^{-}$ions, which compete with $\mathrm{Cl}^{-}$ions in the diffusion layer. The presence and movement of the $\mathrm{Cl}^{-}$counterion in the diffusion layer is favored when the $\mathrm{pH}$ is $3.0 .^{40} \mathrm{MA} 3$ and MA5 membranes achieved high charge density.

The functional groups in $\mathrm{P}(\mathrm{ClVBTA})$ and $\mathrm{P}(\mathrm{SSNa})$ were electrically charged across the entire $\mathrm{pH}$ range. ${ }^{41}$ In general, if the functional IPN concentration is high, the water uptake percent is low because the hydrophobic character increases, and the superficial charges inside the membrane cannot be reached by the ionic solution.

Ion transport evaluation using Donnan dialysis

The mathematical model for the behavior of $\mathrm{Cr}$ (III) was evaluated using the correlation coefficient $\left(\mathrm{R}^{2}\right)$, which was close to 1 in all tests. $\mathrm{R}^{2}$ was low for MPP only when using $\mathrm{NaCl}$ for extraction (see Table 3 ). The concentration polarization effect was neglected due to the sufficiently high stirring speed in each cell chamber. Similar results were obtained when the experimental data of the $\mathrm{Cr}$ (III) ions were fitted to a non-linear curve as the exponential mathematical model using the Leveberg-Marquardt algorithm. ${ }^{42}$

Figure 6 shows the mathematical model fit by the $\mathrm{Cr}(\mathrm{III})$ ions at $\mathrm{pH} 2.0$ in the feed phase, and the extraction phase at $\mathrm{pH} 1.0 \mathrm{Cr}$ (III) can exist as $\mathrm{CrOH}^{2+}$ and $\mathrm{Cr}(\mathrm{OH})_{2}^{+}$at $0.04 \mathrm{~mol} / \mathrm{L} .{ }^{43,44}$ The acidity guarantees total dissolution and $\mathrm{Cr}$ (III) ionization, which prevents the formation of solid precipitate ${ }^{45}$ The Donnan equilibrium for MC1 (see Figure 6a), MC2 (see Figure 6b), MC5 (see Figure 6c), and MC6 (see Figure 6d) membranes was achieved between 250 and 500 minutes, and in the extraction profile curve, the $\mathrm{Cr}$ (III) concentration at equilibrium did not overcome the $\mathrm{Cr}$ (III) concentration at the equilibrium of the feed phase (see Figures 6 a, c, and d). 
The (a) parameter obtained in the mathematical fitting can report the rate of response of the external $\mathrm{Cr}$ (III) ion concentration in both phases (feed and receiving).

To extract the $\mathrm{Cr}(\mathrm{III})$ ion in acid media under the first experimental condition, if the $(\mathrm{k})$ parameter value is low, the (a) parameter value is high. The $\mathrm{MC} 1$ membrane follows this relationship. An inverse relation was obtained for the MC4 membrane. The results for the parameters (a, b, c, and k) from the mathematical model fit are shown in Table 3. Moreover, when the extraction contained chloride (experimental condition 2 for $\mathrm{Cr}(\mathrm{III})$ ), the $(\mathrm{k})$ and (a) parameters were higher than when extracting with nitric acid. When chloride was used as the extracting ion, the MC1 and MC4 membranes showed the same behavior as nitric acid alone.

The (b) parameter, which indicates the partition of the $\mathrm{Cr}(\mathrm{III})$ ion in both phases (feed and receiving), was very similar for both experimental conditions. In both cases, MC2 had the lowest value, and MC3 and MC6 gave high values.

Table3. Constant values for the mathematical model fit using experimental data for $\mathrm{Cr}(\mathrm{III})$ extraction.

\begin{tabular}{|c|c|c|c|c|c|c|c|}
\hline \multirow{2}{*}{$\begin{array}{l}\text { Experimental } \\
\text { condition }\end{array}$} & \multirow[t]{2}{*}{ Sample } & \multicolumn{4}{|c|}{ Estimated parameter } & \multicolumn{2}{|c|}{ Adjustment } \\
\hline & & $k \times 10^{-4}$ & $a \times 10^{-3}$ & $b \times 10^{-1}$ & $c \times 10^{-2}$ & $\underset{\left({ }^{\mathrm{a}}\right)}{\text { Feeding phase }}$ & $\begin{array}{l}\text { Extraction phase } \\
\left(\left(^{b}\right)\right.\end{array}$ \\
\hline & MPP & 7.72 & -8.54 & -9.70 & 3.88 & 0.98 & 0.98 \\
\hline & $\mathrm{MC} 1$ & 82.4 & -7.36 & -3.29 & 1.31 & 0.94 & 0.94 \\
\hline & $\mathrm{MC} 2$ & 91.5 & -7.96 & -2.75 & 1.09 & 0.97 & 0.97 \\
\hline & MC3 & 105.6 & -8.67 & -6.81 & 2.73 & 0.98 & 0.98 \\
\hline & MC4 & 138.6 & -9.58 & -5.12 & 2.05 & 0.98 & 0.99 \\
\hline & MC5 & 115.2 & -8.98 & -4.39 & 1.76 & 0.99 & 0.99 \\
\hline & MC6 & 138.2 & -8.69 & -5.72 & 2.29 & 0.99 & 0.99 \\
\hline \multirow{7}{*}{2} & MPP & 30007.7 & -1.05 & -10.0 & -3.96 & 0.44 & 0.44 \\
\hline & $\mathrm{MC1}$ & 117.7 & -7.49 & -4.39 & 1.76 & 0.96 & 0.95 \\
\hline & $\mathrm{MC} 2$ & 80.62 & -13.1 & -3.73 & 1.49 & 0.97 & 0.98 \\
\hline & MC3 & 150.9 & -8.76 & -5.51 & 2.21 & 0.98 & 0.98 \\
\hline & MC4 & 198 & -9.69 & -6.14 & 2.46 & 0.99 & 0.99 \\
\hline & MC5 & 164.6 & -9.09 & -5.12 & 2.05 & 0.98 & 0.98 \\
\hline & MC6 & 197.4 & -8.76 & -6.36 & 2.54 & 0.99 & 0.99 \\
\hline
\end{tabular}

Figure 7 shows the profile in both phases (feed and receiving) for $\mathrm{Cr}$ (III) when $\mathrm{Na}^{+}$was used as the driving ion force that helped the $\mathrm{H}^{+}$extracting ion. The Donnan equilibrium for MC1 (see Figure 7 a), MC2 (see Figure 7 b), MC5 (see Figure $7 \mathrm{c}$ ), and MC6 (see Figure $7 \mathrm{~d}$ ) membranes was achieved between 300 and $450 \mathrm{~min}$, and in the extraction profile curve, the $\mathrm{Cr}(\mathrm{III})$ concentration at equilibrium overcame the $\mathrm{Cr}$ (III) concentration at equilibrium in the feed phase. However, the modified membrane has a low effect on retaining the Cr(III) ions inside its structure.

The $\mathrm{Na}^{+}$ion improved the extraction of the $\mathrm{Cr}(\mathrm{III})$ ions by $10 \%$ compared to $\mathrm{H}^{+}$ion. The $\mathrm{Na}^{+}$ion replaces or displaces the active sites of the $\mathrm{Cr}$ (III) ions inside the membrane. This effect was higher when the extraction used sodium ion rather than $\mathrm{H}^{+}$

The $\mathrm{Cr}(\mathrm{VI})$ ion species, depending on the concentration in an acid environment ( $\mathrm{pH} 3.0$ ), primarily form $\mathrm{Cr}_{2} \mathrm{O}_{7}{ }^{2-}$ and $\mathrm{HCrO}_{-}^{-45,46} \mathrm{At} \mathrm{pH} 9.0$, mos $\mathrm{Cr}(\mathrm{VI})$ ions are $\mathrm{CrO}_{4}^{2-}$. Figure 8 shows the mathematical model fitting. The model was evaluated using the $\mathrm{R}^{2}$ of both conditions and phases, and all $\mathrm{R}^{2}$ values were near 1 .

At pH 3.0, $\mathrm{Cr}(\mathrm{VI})$ exists mainly as $\mathrm{HCrO}_{4}^{-}$at $0.5 \mathrm{mmol} / \mathrm{L}$. For example, Donnan equilibrium for MA3 (see Figure 8 a), MA5 (see Figure 8 b) and MA7 (see Figure $8 \mathrm{c}$ ) was achieved between 250 to $500 \mathrm{~min}, 150$ to $400 \mathrm{~min}$, and 180 to $220 \mathrm{~min}$ of the extraction, respectively. At the end of the process, the $\mathrm{Cr}(\mathrm{VI})$ ion concentration is higher in the extraction phase than in the feed phase. These results show that the modified membranes can retain $\mathrm{Cr}(\mathrm{VI})$ ions in their structure at $\mathrm{pH}$ 3.0. Table 4 summarizes the a, b, c, and $\mathrm{k}$ parameters at $\mathrm{pH} 3.0$.

The rate of response values for MA2, MA3, MA4, and MA7 were very close to each other, while MA5 and MA6 were extreme values. The (a) parameter indicates the diffusion time for $\mathrm{Cr}(\mathrm{VI})$ through the membrane structure. If the (a) parameter value is low, $\mathrm{Cr}(\mathrm{VI})$ can diffuse easily into the extraction chamber. A large (a) parameter can result from high hydrophobicity, high ion hydration volume, steric hindrance, and a low distribution of fixed charges in the membrane.

The absolute value of the (b) parameter (see Table 4) obtained in the mathematical fitting using the experimental data reports the distribution of $\mathrm{Cr}(\mathrm{VI})$ ions in the feed and extraction phases. MA3 and MA6 achieved the same value of (b), as did MA5 and MA7. However, the rate of membrane response differed at $\mathrm{pH}$ 3.0. The (b) parameter is time-independent. The minimum and maximum values of the (b) parameter were obtained with MA2 and MA4, respectively. The $(\mathrm{k})$ parameter in the mathematical model is the slope factor of the $\mathrm{Cr}(\mathrm{VI})$ concentration in the extraction phase. The negative values in the fitting were due to $\mathrm{Cr}(\mathrm{VI})$ concentration increases as time increased in the extraction phase. However, the values of $(\mathrm{k})$ for all membrane samples were low, indicating that only 30 to $35 \%$ was removed. These results indicate that $\mathrm{Cr}(\mathrm{VI})$ ions were retained inside the membranes.

$\mathrm{Cr}(\mathrm{VI})$ ion transport under such conditions depends on the $\mathrm{P}(\mathrm{ClVBTA})$ network concentration inside the pores; in acidic $\mathrm{pH}$, the influence of percent modification is mainly due to the variation in porosity.

For $\mathrm{pH} 9.0$ in both phases, the parameters from the fitting of the mathematical model are reported in Table 4. Figure 9 shows the mathematical model fitting. The model was evaluated using the $\mathrm{R}^{2}$ value of both conditions and phases. Figure 9 shows the time to Donnan equilibrium. The dotted line indicates the mathematical curve fit for both phases, and the continuous line with points is the experimental data. At $\mathrm{pH} 9.0, \mathrm{Cr}(\mathrm{VI})$ exists only as $\mathrm{CrO}_{4}^{2-}$ at $0.5 \mathrm{mmol} / \mathrm{L}$.

The experimental data for the MPP membrane cannot be fit to the mathematical model $\left(\mathrm{R}^{2}=0.44\right)$ because the membrane is hydrophobic, and $\mathrm{Cr}(\mathrm{VI})$ ion diffusion only occurs when the MPP is impregnated with ethanol. The ethanol diffuses out of the MPP rapidly. Donnan equilibrium for MA3 (see Figure 9 a), MA5 (see Figure 9 b) and MA7 (see Figure 9 c) was achieved between 320 and $600 \mathrm{~min}, 110$ and $320 \mathrm{~min}$, and 310 and $450 \mathrm{~min}$ of extraction, respectively. The modified membranes at $\mathrm{pH} 9.0$ can produce low retention in the structure compared to the extraction at $\mathrm{pH}$ 3.0. These $\mathrm{Cr}(\mathrm{VI})$ ions compete against hydroxyl and chloride ions during ion exchange within the membrane; the extraction capacity at $\mathrm{pH} 9.0$ increases by $20 \%$ to $30 \%$ compared to the extraction at $\mathrm{pH} 3.0$. The $\mathrm{R}^{2}$ values of the modified membranes are near 1 . Table 4 reports the a, b, c, and k parameters at $\mathrm{pH} 9.0$.

For example, the values of the $(\mathrm{k})$ parameter for these experimental conditions were higher than the values obtained at $\mathrm{pH} 3.0$ using the same membranes. MA7 and MA3 achieved the highest and lowest value of (k), respectively. Under this condition, removal between 50 and $70 \%$ was obtained. The membrane does not have a retention effect at $\mathrm{pH} 9.0$ because the main driving force is the concentration gradient. 

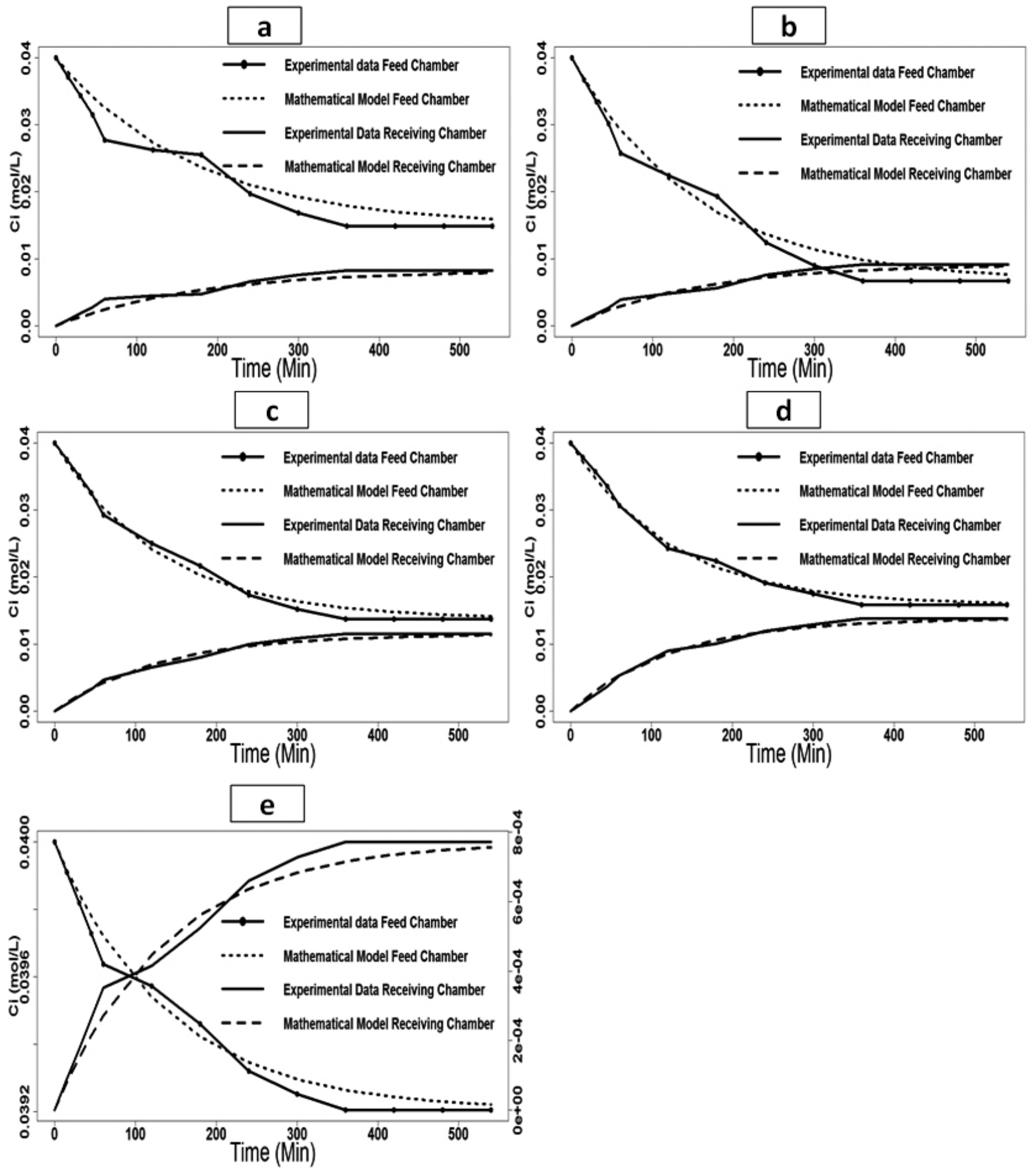

Figure 6. Experimental data for the Cr(III) ion concentration in both phases (feed and receiving) fitted to the mathematical model using modified membranes with $\mathrm{P}(\mathrm{SSNa})$ : a. MC1; b. MC2; c. MC5; d. MC6; and e. MPP at $\mathrm{pH} 2.0$ in the feed phase and extraction phase at $\mathrm{pH} 1.0$. $\mathrm{H}^{+}$is the extracting ion. 

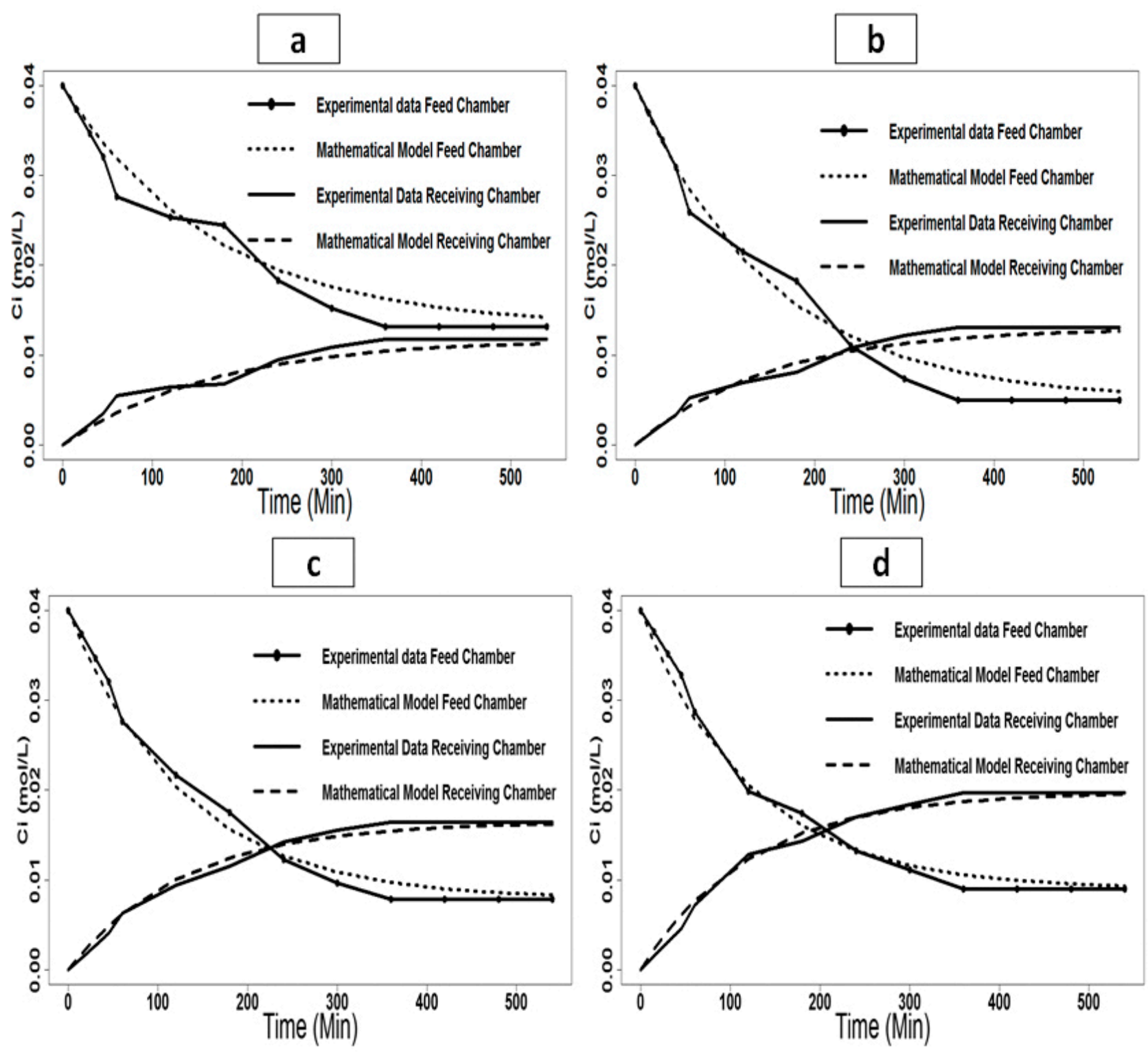

Figure 7. Experimental data for the $\mathrm{Cr}$ (III) ion concentration in both phases (feed and extraction) fitted to the mathematical model using modified membranes with P(SSNa): a. MC1; b. MC2; c. MC5; and d. MC6 at pH 2.0. $\mathrm{Na}^{+}$is the driving ion force that assists the $\mathrm{H}^{+}$extracting ion.

Moreover, the (a) parameter for the transport of $\mathrm{Cr}(\mathrm{VI})$ ions shows higher values for the rate of response at $\mathrm{pH} 9.0$ than at $\mathrm{pH} 3.0$. The values of the (a) parameter depend on the internal morphology and modification percentage degree of the membranes because the internal structure can help the diffusion of $\mathrm{Cr}(\mathrm{VI})$. MA3 achieves the highest rate of response and MA7 the lowest.

If the (a) parameter value is high, then the transport test is faster to achieve convergence of the $(\mathrm{k})$ parameter, in both experimental conditions $(\mathrm{pH} 3.0$ and $\mathrm{pH} 9.0)$.

The (b) parameter for the extraction at $\mathrm{pH} 9.0$ indicates the partitioning of the $\mathrm{Cr}(\mathrm{VI})$ ions in the feed and extraction phases. The MA3 achieves low values for the (k) and (b) parameters, but a high value for the (a) parameter. It is possible that MA3 has retention behaviour in the internal structure. MA7 achieves high values for the (b) and (k) parameters, but a low value for the (a) parameter. The morphology of the functional network change depends on the $\mathrm{pH}$ of the solution. Moreover, MA4 and MA6 achieve very similar values of (b). The Stokes radius of hydration of $\mathrm{Cr}(\mathrm{VI})$ at $\mathrm{pH} 3.0\left(\mathrm{HCrO}_{4}^{-}, 0.375 \mathrm{~nm}\right)$ and $\mathrm{pH} 9.0\left(\mathrm{CrO}_{4}^{2-}, 0.240 \mathrm{~nm}\right)$ produce one effect in the transport through the membranes because the size difference causes friction during the movement and a strong electrostatic force during the ion exchange. ${ }^{47}$ All of these features produce a retention effect.

The (c) parameter in the mathematical model fitting has the function of the correction of the fitting. This parameter can be understood as an approximation of the extraction target ion concentration when the feed phase does not have the target ion concentration. The main function of (c) is to reduce the slant and the error of the fitting to zero. If the (c) parameter is not considered, the error value will be the (c) constant. These results are shown in Table 3 and Table 4. 

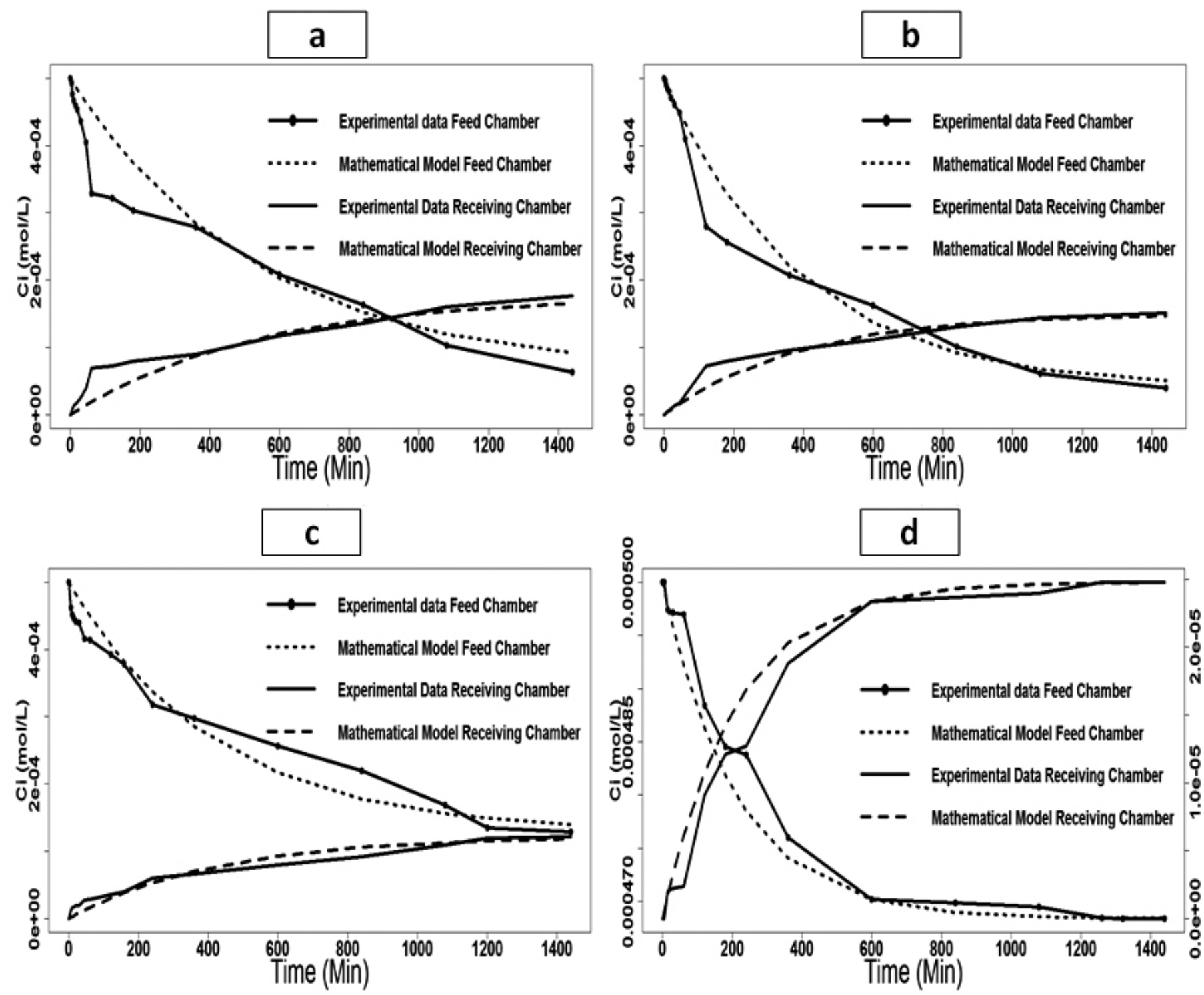

Figure 8. Experimental data for the $\mathrm{Cr}(\mathrm{VI})$ ion concentration in both phases (feed and extraction) fitted to the mathematical model at pH 3.0 , using the modified membranes with P(CIVBTA): a. MA3; b. MA5; c. MA7; and d. MPP.

\section{CONCLUSIONS}

Modified MPP membranes with $\mathrm{P}(\mathrm{ClVBTA})$ and $\mathrm{P}(\mathrm{SSNa})$ have ion exchange capacities and there can be obtained using radical polymerization. The crosslinker reagent concentrations can control the functional network density, as demonstrated using SEM, volumetric flux, and water uptake percentage.

When Cr(III) transport was analyzed and $0.1 \mathrm{~mol} / \mathrm{L} \mathrm{HNO}_{3}$ was used as the extraction agent, MC4 achieved the highest extraction because the value of $\mathrm{k}\left(138.6 \times 10^{-4}\right)$ is highest in comparison with the other functional $\mathrm{P}(\mathrm{SSNa})$ membranes tested. However, when $\mathrm{Cr}$ (III) transport was analysed and a 0.01 $\mathrm{mol} / \mathrm{L} \mathrm{HNO}_{3}$ and $1 \mathrm{~mol} / \mathrm{L} \mathrm{NaCl}$ mixture was used as the extraction agent, MC4 achieved the highest extraction because the $\mathrm{k}$ value $\left(198 \times 10^{-4}\right)$ is highest in comparison with the other functional $\mathrm{P}(\mathrm{SSNa})$ membranes tested. However, MC4 achieved an (a) value of $-9.69 \times 10^{-3}$, which is not the lowest.

For $\mathrm{Cr}(\mathrm{VI})$ transport at $\mathrm{pH}$ 3.0, MA6 achieved the highest extraction because the value of $\mathrm{k}\left(1.79 \times 10^{-4}\right)$ is highest in comparison with the other functional $\mathrm{P}(\mathrm{ClVBTA})$ membranes tested. However, when $\mathrm{Cr}(\mathrm{VI})$ transport was analysed $\mathrm{pH} 9.0, \mathrm{MA} 7$ achieved the highest extraction because the k value $\left(3.55 \times 10^{-4}\right)$ is highest in comparison with the other functional P(CIVBTA) membranes tested.

\section{ACKNOWLEDGEMENTS}

The authors thank FONDECYT (Grant No 1150510). Julio Sánchez thanks FONDECYT (Grant No 11140324) and DICYT (Grant No 021741SP), VRIDEI, Universidad de Santiago de Chile. 
Table 4. Constant values of the mathematical model fit using the experimental data for $\mathrm{Cr}(\mathrm{VI})$ extraction.

\begin{tabular}{|c|c|c|c|c|c|c|c|}
\hline \multirow[t]{2}{*}{ Experimental condition } & \multirow[t]{2}{*}{ Sample } & \multicolumn{4}{|c|}{ Estimated parameter } & \multicolumn{2}{|c|}{ Adjustment } \\
\hline & & $k \times 10^{-4}$ & $a \times 10^{-3}$ & $b \times 10^{-1}$ & $c \times 10^{-4}$ & $\begin{array}{l}\text { Feeding phase } \\
\left({ }^{\mathrm{a}}\right)\end{array}$ & Extraction phase $\left({ }^{b}\right)$ \\
\hline \multirow{7}{*}{3} & MPP & 0.28 & -3.94 & -7.84 & 3.9 & 0.44 & 0.44 \\
\hline & MA2 & 1.53 & -3.17 & -3.14 & 1.57 & 0.98 & 0.98 \\
\hline & MA3 & 1.77 & -1.89 & -4.05 & 2.0 & 0.99 & 0.99 \\
\hline & MA4 & 1.64 & -1.93 & -4.57 & 2.28 & 0.99 & 0.99 \\
\hline & MA5 & 1.53 & -1.5 & -3.29 & 1.64 & 0.98 & 0.99 \\
\hline & MA6 & 1.79 & -6.32 & -4.05 & 2.03 & 0.97 & 0.96 \\
\hline & MA7 & 1.22 & -2.4 & -3.29 & 1.64 & 0.97 & 0.98 \\
\hline \multirow{7}{*}{4} & MPP & 0.25 & -1.72 & -9.62 & 4.81 & 0.98 & 0.98 \\
\hline & MA2 & 2.85 & -3.21 & -6.81 & 3.41 & 0.98 & 0.98 \\
\hline & MA3 & 1.75 & -1.04 & -3.75 & 1.87 & 0.99 & 0.99 \\
\hline & MA4 & 2.72 & -1.22 & -5.51 & 2.76 & 0.97 & 0.98 \\
\hline & MA5 & 3.15 & -1.17 & -7.05 & 3.52 & 0.99 & 0.98 \\
\hline & MA6 & 2.49 & -1.07 & -5.72 & 2.86 & 0.99 & 0.99 \\
\hline & MA7 & 3.55 & -4.00 & -7.84 & 3.92 & 0.99 & 0.99 \\
\hline
\end{tabular}
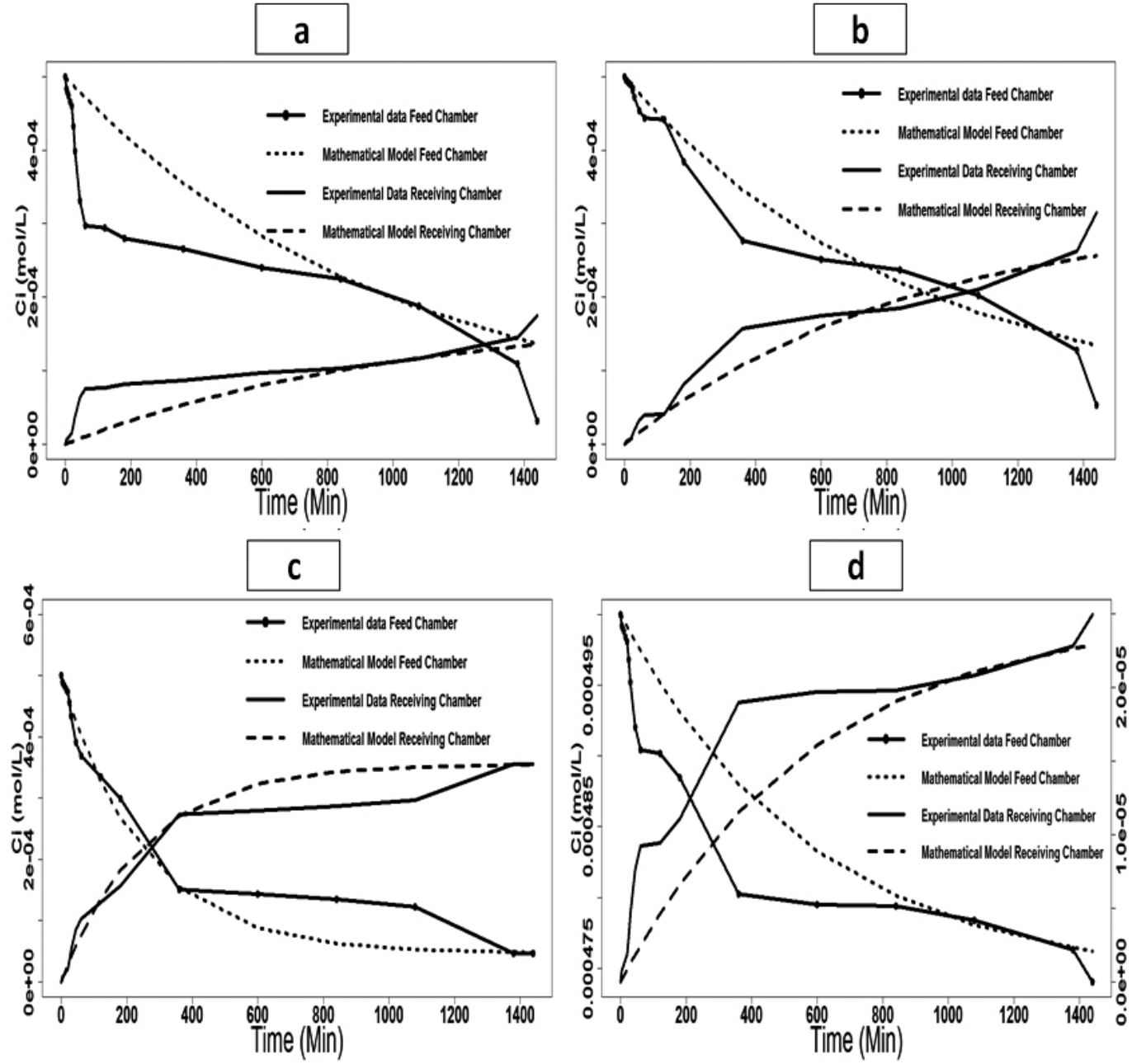

Figure 9. Experimental data's of the $\mathrm{Cr}(\mathrm{VI})$ ions concentration in both phases (feed and extraction) fitted to the mathematical model at $\mathrm{pH}$ 9.0, using the modified membranes with P(CIVBTA). a. MA3. b. MA5. c. MA7. d. MPP. 


\section{REFERENCES}

1. S. Ballesteros, J. M Rincón, B. Rincón-Mora, M. Jordán, Vitrification of urban soil contamination by hexavalent chromium, J. Geochem. Explor. 2016.

2. WHO, Guidelines for Drinking Water Quality, in, World Health Organization, Genova, Italy, 2008.

3. W. Jin, H. Du, S. Zheng, Y. Zhang, Electrochemical processes for the environmental remediation of toxic Cr (VI): A review, Electrochim. Acta. 191, 1044, (2016)

4. R. B. García-Reyes, J. R. Rangel-Mendez, M. C. Alfaro-De la Torre, Chromium (III) uptake by agro-waste biosorbents: Chemical characterization, sorption-desorption studies, and mechanism, J. Hazard. Mater. 170, 845, (2009)

5. A. Golder, A. Samanta, S. Ray, Removal of trivalent chromium by electrocoagulation, Sep. Purif. Technol. 53, 33, (2007)

6. R. R Patterson, S. Fendorf, M. Fendorf, Reduction of hexavalent chromium by amorphous iron sulfide, Environ. Sci Technol. 31, 2039, (1997)

7. D. Park, S.-R. Lim, Y.-S. Yun, J.M. Park, Reliable evidences that the removal mechanism of hexavalent chromium by natural biomaterials is adsorption-coupled reduction, Chemosphere. 70, 298, (2007)

8. S. A. Cavaco, S. Fernandes, M. M. Quina, L. M. Ferreira, Removal of chromium from electroplating industry effluents by ion exchange resins, $J$. Hazard. Mater. 144, 634, (2007)

9. A. Figoli, J. Hoinkis, J. Bundschuh, Membrane Technologies for Water Treatment: Removal of Toxic Trace Elements with Emphasis on Arsenic, Fluoride and Uranium, CRC Press. London, UK, 2016

10. M. San Román, E. Bringas, R. Ibanez, I. Ortiz, Liquid membrane technology: fundamentals and review of its applications, J. Chem. Technol. Biot. 85, 2, (2010)

11. E. H Cwirko, R. G. Carbonell, A theoretical analysis of Donnan dialysis across charged porous membranes, J. Membr. Sci. 48, 155, (1990)

12. K. Pyrzynska, Preconcentration and recovery of metal ions by Donnan dialysis, Microchim Acta. 153, 117, (2006)

13. A. Tor, Y. Cengeloğlu, M. Ersöv, G. Arslan, Transport of chromium through cation-exchange membranesby Donnan dialysis in the presence of some metals of different valences, Desalination. 170, 151, (2004)

14. M. J. Hatch, J. A. Dillon, Acid retardation. Simple physical method for separation of strong acids from their salts, Ind. Eng. Chem. Process Des. Dev. 2, 253, (1963)

15. J. Mathur, M. Murali, M.B. Krishna, V. Ramachandhran, M. Hanra, B. Misra, Diffusion dialysis aided electrodialysis process for concentration of radionuclides in acid medium, J. Radioanal. Nucl. Chem. 232, 237, (1998)

16. A. A. Said, M. Amara, H. Kerdjoudj, The effect of thiourea as a complexing agent on the separation of metallic ions through cation exchange membranes by Donnan dialysis, Ionics. 19, 177, (2013)

17. S. Velizarov, J. G. Crespo, M. A. Reis, Removal of inorganic anions from drinking water supplies by membrane bio/processes, Rev. Environ. Sci. Bio/Technol. 3, 361, (2004)

18. L. Chikh, V. Delhorbe, O. Fichet, (Semi-) Interpenetrating polymer networks as fuel cell membranes, J. Membr. Sci. 368, 1, (2011)

19. N. Sahiner, W. Godbey, G. L. McPherson, V. T. John, Microgel, nanogel and hydrogel-hydrogel semi-IPN composites for biomedical applications: synthesis and characterization, Colloid Polym. Sci. 284, 1121, (2006)

20. A. Bajpai, J. Bajpai, S. Shukla, Water sorption through a semiinterpenetrating polymer network (IPN) with hydrophilic and hydrophobic chains, React. Funct. Polym. 50, 9, (2002)

21. B. Krajewska, Application of chitin-and chitosan-based materials for enzyme immobilizations: a review, Enzyme Microb. Technol. 35, 126, (2004)

22. C. O. M'Bareck, Q. T. Nguyen, S. Alexandre, I. Zimmerlin, Fabrication of ion-exchange ultrafiltration membranes for water treatment: I. Semiinterpenetrating polymer networks of polysulfone and poly (acrylic acid), J. Membr. Sci. 278, 10, (2006)

23. G. Couture, A. Alaaeddine, F. Boschet, B. Ameduri, Polymeric materials as anion-exchange membranes for alkaline fuel cells, Prog. Polym. Sci. 36, 1521, (2011)

24. Y. S. Dzyazko, S. L. Vasilyuk, L. M. Rozhdestvenskaya, V. N. Belyakov, N. V. Stefanyak, N. Kabay, M. Yüksel, Ö. Arar, Ü. Yüksel, Electrodeionization of $\mathrm{Cr}$ (VI)-Containing Solution. Part II: Chromium transport through inorganic ion-exchanger and composite ceramic membrane, Chem. Eng. Commun. 196, 22, (2008)
25. J. Sánchez, B. L. Rivas, Liquid-Phase Polymer-Based Retention of Chromate and Arsenate Oxy-Anions, in: Macromol. Symp. Wiley Online Library, 2012; pp. 123-136.

26. Y. Tapiero, B. L. Rivas, J. Sánchez, M. Bryjak, N. Kabay, Polypropylene membranes modified with interpenetrating polymer networks for the removal of chromium ions, J. Appl. Polym. Sci. 132, 41953, (2015)

27. B. L. Rivas, E. D. Pereira, M. Palencia, J. Sánchez, Water-soluble functional polymers in conjunction with membranes to remove pollutant ions from aqueous solutions, Prog. Polym. Sci. 36, 294, (2011)

28. J. Neter, M. H. Kutner, C. J. Nachtsheim, W. Wasserman, Applied linear statistical models, Irwin, Chicago, 1996.

29. W. M. Deen, Analysis of transport phenomena (topics in chemical engineering), Oxford University Press, New York, USA, 1998.

30. M. Bryjak, I. Duraj, Anion-exchange membranes for separation of borates by Donnan dialysis, Desalination. 310, 39, (2013)

31. O. Thomas, C. Burgess, UV-visible Spectrophotometry of Water and Wastewater, Elsevier., Amsterdam, Netherlands, 2007.

32. A. Szymczyk, P. Fievet, J. Reggiani, J. Pagetti, Electrokinetic characterization of mixed alumina-titania-silica MF membranes by streaming potential measurements, Desalination. 115, 129, (1998)

33. H. Matsuyama, M. Yuasa, Y. Kitamura, M. Teramoto, D.R. Lloyd, Structure control of anisotropic and asymmetric polypropylene membrane prepared by thermally induced phase separation, J. Membr. Sci. 179, 91, (2000)

34. C. C. Wang, F.L. Yang, L. F. Liu, Z. M. Fu, Y. Xue, Hydrophilic and antibacterial properties of polyvinyl alcohol/4-vinylpyridine graft polymer modified polypropylene non-woven fabric membranes, J. Membr. Sci. 345, 223, (2009)

35. Q. Yang, Z. -K. Xu, Z. -W. Dai, J. -L. Wang, M. Ulbricht, Surface modification of polypropylene microporous membranes with a novel glycopolymer, Chem. Mater. 17, 3050, (2005)

36. J. Schauer, J. Hnát, L. Brožová, J. Žitka, K. Bouzek, Heterogeneous anion-selective membranes: Influence of a water-soluble component in the membrane on the morphology and ionic conductivity, J. Membr. Sci. 401, 83, (2012)

37. T. Maddanimath, I. S. Mulla, S. R. Sainkar, K. Vijayamohanan, K. I. Shaikh, A. S. Patil, S. P. Vernekar, Humidity sensing properties of surface functionalized polyethylene and polypropylene films, Sens. Actuators, B. 81, 141, (2002)

38. A. Szymczyk, P. Fievet, J. Reggiani, J. Pagetti, Characterisation of surface properties of ceramic membranes by streaming and membrane potentials, J. Membr. Sci. 146, 277, (1998)

39. K. Hu, J. M. Dickson, Modelling of the pore structure variation with $\mathrm{pH}$ for pore-filled $\mathrm{pH}$-sensitive poly (vinylidene fluoride)-poly (acrylic acid) membranes, J. Membr. Sci. 321, 162, (2008)

40. H. -Y. Yu, Z. -K. Xu, Q. Yang, M. -X. Hu, S. -Y. Wang, Improvement of the antifouling characteristics for polypropylene microporous membranes by the sequential photoinduced graft polymerization of acrylic acid, J. Membr. Sci. 281, 658, (2006)

41. D. H. Kim, S. -H. Moon, J. Cho, Investigation of the adsorption and transport of natural organic matter (NOM) in ion-exchange membranes, Desalination. 151, 11, (2003)

42. Y. Tapiero, B. L. Rivas, J. Sánchez, Functional ion membranes supported inside microporous polypropylene membranes to transport chromium ions: determination of mass transport coefficient, J. Chil. Chem. Soc. 59, 2737, (2014)

43. C. Fontàs, I. Queralt, M. Hidalgo, Novel and selective procedure for $\mathrm{Cr}$ (VI) determination by X-ray fluorescence analysis after membrane concentration, Spectrochim. Acta, part B. 61, 407, (2006)

44. W. G. Cook, R. P. Olive, Pourbaix diagrams for chromium, aluminum and titanium extended to high-subcritical and low-supercritical conditions, Corros. Sci. 58, 291, (2012)

45. M. Owlad, M. K. Aroua, W. A. W. Daud, S. Baroutian, Removal of hexavalent chromium-contaminated water and wastewater: a review, Water, Air, Soil Poll. 200, 59, (2009)

46. J. Kotaś, Z. Stasicka, Chromium occurrence in the environment and methods of its speciation, Environ. Pollut. 107, 263, (2000)

47. Y. Marcus, Thermodynamics of solvation of ions. Part 5.-Gibbs free energy of hydration at 298.15 K, J. Chem. Soc., Faraday Trans. 87, 2995, (1991) 